\title{
Changes in Production Potential in China in Response to Climate Change from 1960 to 2010
}

\author{
Luo Liu, ${ }^{1,2,3}$ Xi Chen, ${ }^{2}$ Xinliang Xu, ${ }^{1}$ Yong Wang, ${ }^{1}$ Shuang Li, ${ }^{1,3}$ and Ying Fu ${ }^{1,3}$ \\ ${ }^{1}$ State Key Laboratory of Resources and Environmental Information System, \\ Institute of Geographic Sciences and Natural Resources Research, Chinese Academy of Sciences, Beijing 100101, China \\ ${ }^{2}$ State Key Laboratory of Desert and Oasis Ecology, Xinjiang Institute of Ecology and Geography, Chinese Academy of Sciences, \\ Urumqi 830011, China \\ ${ }^{3}$ University of Chinese Academy of Sciences, Beijing 100049, China
}

Correspondence should be addressed to Xinliang Xu; xuxl@lreis.ac.cn

Received 9 December 2013; Accepted 27 January 2014; Published 5 March 2014

Academic Editor: Dong Jiang

Copyright (C) 2014 Luo Liu et al. This is an open access article distributed under the Creative Commons Attribution License, which permits unrestricted use, distribution, and reproduction in any medium, provided the original work is properly cited.

From the Global Agro-Ecological Zone (GAEZ) model, changes in the three climate factors (temperature, precipitation, and solar radiation) over the past five decades showed different trends and that production potential was impacted significantly by the geographic heterogeneity of climate change. An increase of approximately 1.58 million tons/decade in production potential correlated with climate change. Regions with increased production potential were located mainly in the Northeast China Plain, the northern arid and semiarid region, and the Huang-Huai-Hai Plain. Regions with decreased production potential were located mainly in the Middle-lower Yangtze Plain and southern China. The climate factors that impacted production potential varied by region. In the Northeast China Plain, increased temperature was the major cause of the increased production potential. In the northern arid and semiarid region, temperature and precipitation were the major factors affecting production potential, but their effects were in opposition to each other. In southern China, increased temperature and decreased solar radiation caused a decreased production potential. In the Middle-lower Yangtze Plain, a decrease in solar radiation was the major factor resulting in decreased production potential. In the Huang-Huai-Hai Plain, changes in temperature and solar radiation had large but opposite effects on production potential.

\section{Introduction}

Annual anomalies in global land-surface air temperatures indicate a warming trend of $0.27^{\circ} \mathrm{C}$ per decade since 1979 , with the greatest warming occurring during the winter and spring in the Northern Hemisphere [1]. The effects of this change in temperature on crop growth and production are uncertain.

China has a population of approximately 1.3 billion people, which is expected to increase and then stabilize at approximately 1.5 billion people in the year 2030 [2]. However, the land area suited for agriculture in China is relatively small. Per capita cultivated land is only 0.12 ha, less than half of the world average [3]. The need to provide food for the large population in China has attracted significant attention $[4,5]$. Moreover, the rapidly increasing demand for food and energy has put heavy pressure on natural resources and caused unprecedented environmental degradation. Government policy has long focused on securing a high level of national self-sufficiency especially in grain food production. Attention to the effects of climate change on agricultural production potential over the past few decades throughout China is needed so that sensible agricultural policies can be formulated for the future [6].

The effects of climate change trends on climate-crop relationships and the yields of major crops across China have been investigated over the past few decades [7-9]. In other studies, the Global Agro-Ecological Zone (GAEZ) model was used to assess the impact of climate change on agricultural land productivity $[10,11]$. However, these studies addressed only the yields of single crops, such as rice, wheat, or maize, and ignored the multiple cropping systems that are used 
on nearly half of the cultivated land in China. A study of the impact of climate change on the overall agricultural production in China at the national and regional levels is yet to be performed.

In this study, meteorological data from 1960 to 2010, including terrain elevation, soil, and farmland distribution data in 2010, were used to calculate the agricultural production potentials in various regions of China based on the GAEZ model, which takes multiple factors into consideration, including light, temperature, moisture, $\mathrm{CO}_{2}$ fertilization, pests, diseases, soil, and topography. Subsequently, the calculated production potentials were verified using official data on actual productivity. Finally, we analyzed the spatialtemporal changes in the production potential in response to climate change during the past five decades. Our results reveal the impact of climate change on agricultural production and the relationship between climate change and wheat yields. This information will not only help to optimize agricultural practices but also allow adaptation to climate change and the development of national food security policies in China.

\section{Materials and Methods}

2.1. Data Sources. The input data for this study included terrain elevation, soil, land-use, and meteorological data. The meteorological data included the monthly maximum air temperature, minimum air temperature, precipitation, relative humidity, wind speed, and hours of sunshine.

A 2010 land-use database, with a mapping scale of $1: 1,000,000$, was developed by the Chinese Academy of Sciences (CAS). The primary data source for the land-use database was Landsat MSS/TM/ETM CCD digital images. Images from the China-Brazil Earth Resources Satellite (CBERS) and Small Satellite Constellation for Environment and Disaster Monitoring and Forecasting (SSCEDMF) HJ1 satellite were also used as a supplement for the land areas not covered by the Landsat images. The land-use data were classified into 25 categories that were subsequently grouped into six classes: cropland, woodland, grassland, water body, built-up area, and unused land. Detailed information about this land-use database can be found in previous reports $[3,12-$ 15]. Farmland data were extracted from the land-use data for this study.

Meteorological data for the period from 1960 to 2010, including the monthly maximum air temperature, minimum air temperature, precipitation, relative humidity, wind speed at $10 \mathrm{~m}$ height, and hours of sunshine, were obtained from national agrometeorological stations maintained by the Chinese Meteorological Administration (CMA) (http://cdc.cma.gov.cn/). Because of the diverse terrain across China, the impact of topography on the interpolation of the meteorological data was also considered. The ANUSPLIN software $[16,17]$, which was designed for spatial interpolation of climate data, was used in this study to interpolate the meteorological data based on the terrain elevation dataset. The monthly data for the above six key plant growth factors were interpolated to $10 \mathrm{~km}$ resolution using the ANUSPLIN software based on the digital terrain model of China.
The terrain elevation dataset derived from the Shuttle Radar Topography Mission (SRTM) C-band data was the first publicly available near-global, high resolution raster Digital Elevation Model (DEM) [18]. The SRTM data were publicly distributed with a $90 \mathrm{~m}$ spatial resolution around the Earth, reduced from the original $30 \mathrm{~m}$ resolution via averaging and subsampling. SRTM data were used for environmental analyses in numerous previous studies.

Soil data were used to calculate the soil-water balance, which was used to determine the potential and actual evapotranspiration for a reference crop and the duration of its growing period. Soil quality was determined based on several parameters, including soil type, effective depth, and water-holding capacity. A nationwide soil dataset, at a scale of $1: 1,000,000$, was provided by the Data Center for Resources and Environmental Sciences (RESDC) at the Chinese Academy of Sciences.

2.2. Methodology. Simulation of the potential productivity of wheat, maize, rice, sweet potato, and soybean was performed at a spatial resolution of $1 \mathrm{~km}$ using the Global Agro-Ecological Zones (GAEZ) model which was developed in the 1970s and updated in 2010 by the Food and Agriculture Organization (FAO) and the International Institute for Applied Systems Analysis (IIASA) [19-22]. These five crops are major crops in China, providing $97.7 \%$ of the total grain output of China. The GAEZ model is based on principles of land evaluation. It utilizes meteorological, terrain elevation, soil, and farmland distribution data to calculate the potential productivity, which is dependent upon the supply of water, energy, nutrients, and physical support to plants.

In the GAEZ model, agroclimatic potential yields are determined using mainly the seasonal temperature and the availability of solar radiation, while additional limitations imposed by water availability, soil characteristics, and terrain slopes determine the actual yields that are obtained under rain-fed conditions. To ensure that only areas suitable for agriculture were assessed for heat stress, only cells with actual yields greater than $20 \%$ of the potential yields and in which at least $5 \%$ of the cell area was cultivated were considered. The optimal crop species were determined by simulating yields for all possible combinations and then selecting the highest yield in each grid cell based on the climate data from 1960 to 2010. We considered irrigated conditions to be appropriate for rice because most rice crops are cultivated under irrigation. For other crops, we considered both irrigated and rain-fed conditions. For crops grown under rain-fed conditions, the date of crop sowing is highly dependent on the presence of sufficient soil moisture for seed germination and seedling establishment. Winter and spring wheat, maize, and maize varieties with an affinity for heat were tested in each grid cell and the crop with the highest productivity was selected. Production potentials of the various crops were calculated using different methods. To calculate the production potential of each crop, growth parameters were adopted based on the growth habits of each crop, including growing period, leaf area index, and harvest index. 


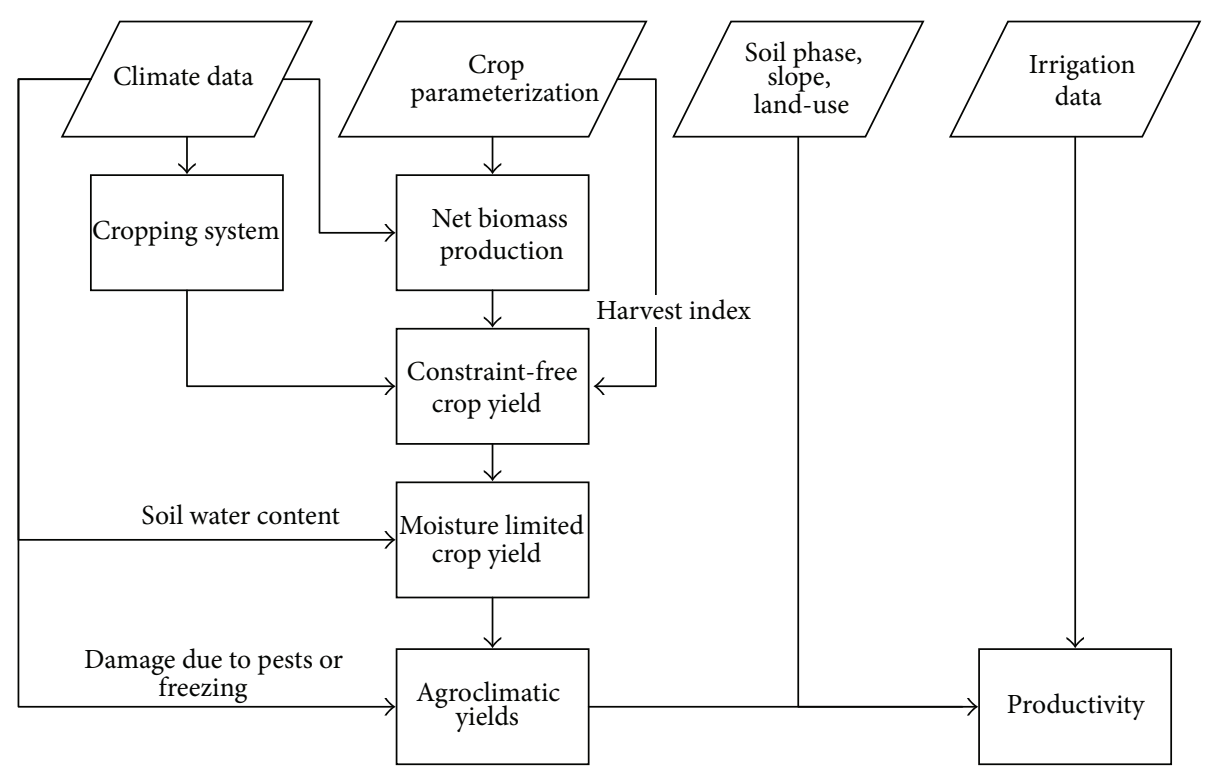

FIGURE 1: Flowchart for calculating potential productivity using the GAEZ model.

China is one of the largest countries and has the highest multiple cropping index [23]. The use of multiple cropping systems in China was considered in the calculation of the potential productivity.

To reveal the impact of water conditions on the production potential, irrigated and rain-fed scenarios were considered. Calculations of production potential for the rainfed scenarios [24] were based on light, temperature, and water conditions, while the calculations for the irrigated scenarios [25] used only the light and temperature conditions assuming sufficient water for crop growth and no water stress. The two scenarios were consistent with existing agricultural management methods used in China for naturally rainfed farmland and irrigated farmland. The equation used to calculate crop yields within each grid cell under rain-fed and irrigated scenarios was

$$
\text { yield }_{\text {total }}=\text { yield }_{\text {rain-fed }}(1-i)+\text { yield }_{\text {irrigated }} \times i,
$$

where yield total $_{\text {is }}$ the production potential within each grid cell $(\mathrm{kg} / \mathrm{ha})$, yield ${ }_{\text {rain-fed }}$ is yields under rain-fed scenarios within each grid cell $(\mathrm{kg} / \mathrm{ha})$, yield irrigated $_{\text {is }}$ yields under irrigated scenarios within each grid cell (kg/ha), and $i(\%)$ is the ratio of irrigation-cultivated area to total cultivated area based on official statistics of the Chinese Agriculture Ministry (Figure 1).

\section{Results}

3.1. Verification. To verify the accuracy of our calculated results, the calculated production potential in 2010 was compared with the actual production as reported in official statistics for 2010. The average potential production per hectare in 2010 was $8,316 \mathrm{~kg} / \mathrm{ha}$, which was nearly 1.55 -fold higher than the actual production. The correlation between the calculated production potential and the actual production is shown in Figure 2. The cross-correlation coefficient was 0.82 and the standard deviation was 74,000 tons, indicating a good correlation. Consequently, the trend of the calculated production potential reflected, to a great extent, the trend of the actual production.

3.2. Spatial Patterns of Production Potential in China. Based on the GAEZ model, production potential values were calculated for each year based on the climatic conditions from 1961 to 2000. A map of the geographic distribution of production potential in 2010 is shown in Figure 3. In 2010, the total production potential in China was 1.17 billion tons and per hectare production potential was $7,889 \mathrm{~kg} / \mathrm{ha}$. The spatial pattern of the production potential was complex, with increasing production potential from north to south and from west to east. The production potential in the southeastern areas was high due to relatively high temperatures and abundant rainfall. The production potential declined with increasing distance from the coast line. In the northwestern part of the country, the production potential was constrained by low temperatures and rainfall. The Middle-lower Yangtze Plain had the greatest total production potential, 0.30 billion tons. In contrast, the area with the least total production potential was the Qinghai-Tibet Plateau, at 4.23 million tons. The area with the greatest per hectare production potential was the Middle-lower Yangtze Plain, at 10,789 kg/ha. In contrast, the area with the least per hectare production potential was the Qinghai-Tibet Plateau, at 3,674 kg/ha (Figure 4).

3.3. Climate Change in China Since 1960. In this study, changes in annual temperature, precipitation, and solar radiation in the major cultivation areas over the past five decades were analyzed statistically. The trends for changes in the climate parameters over the period are shown in Figure 5. Overall, temperature showed an obvious increasing trend 


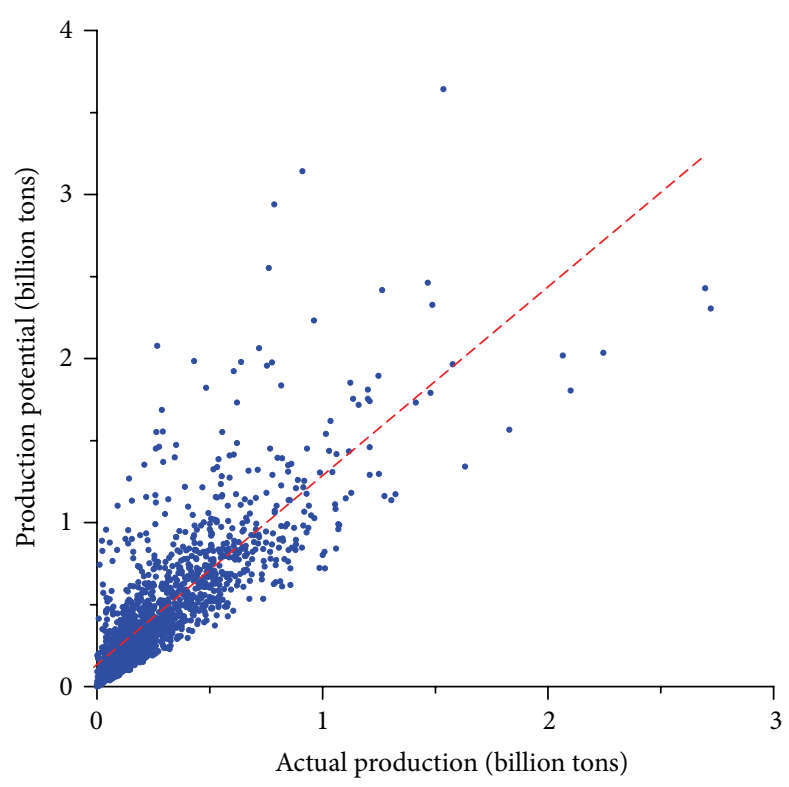

FIGURE 2: Correlation between production potential and actual production.

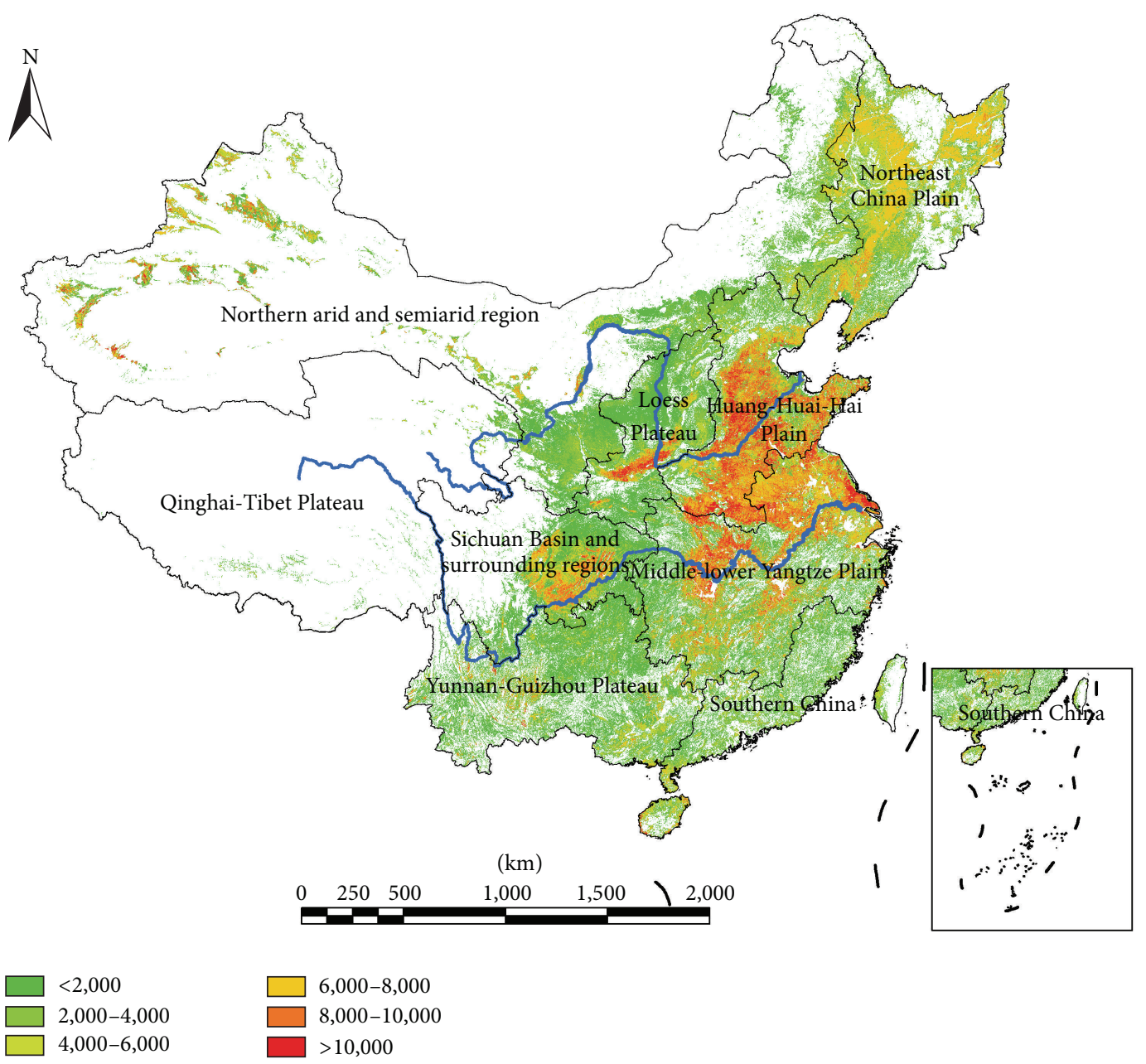

FIGURE 3: Distribution of production potential in China in $2010(\mathrm{~kg} / \mathrm{ha})$. 


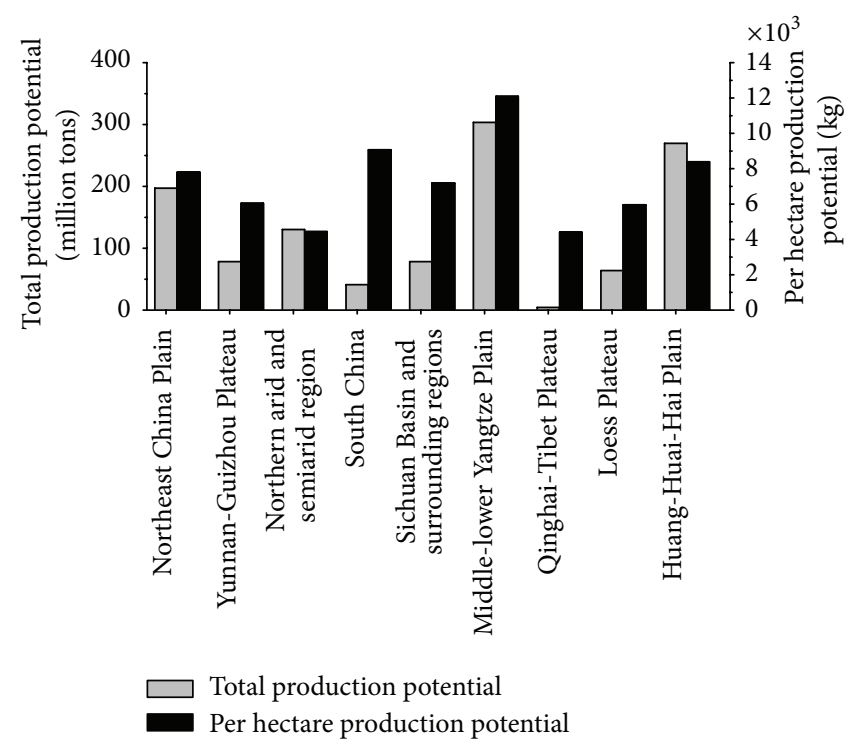

FIgURE 4: Production potential of various regions in 2010.

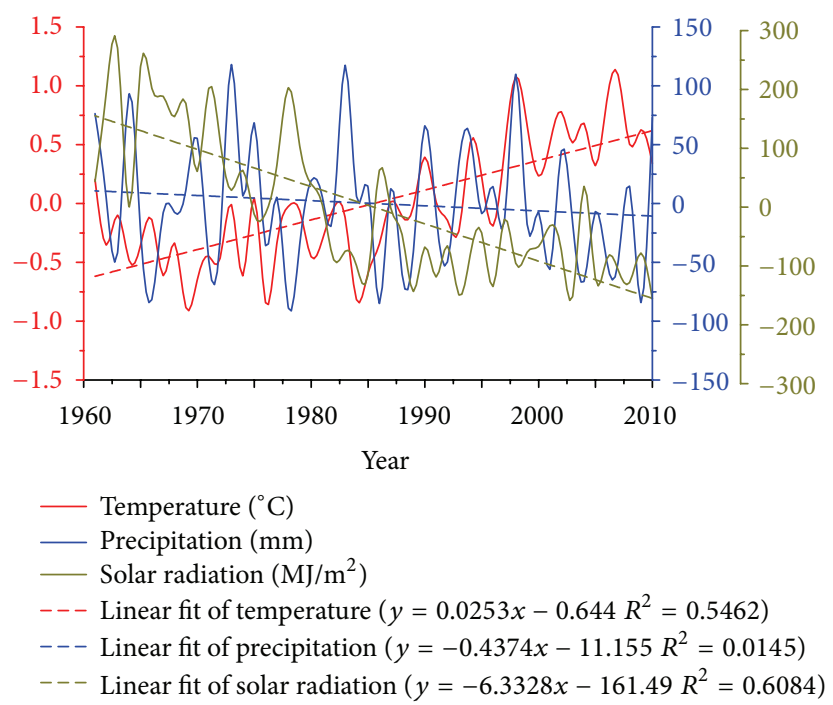

FIgURE 5: Annual anomaly maps of each climatic factor during the past five decades.

since the late 1960s, and the rate of temperature change increased dramatically after the late 1980 s relative to the prior years. Mean temperature increased by $0.25^{\circ} \mathrm{C} /$ decade in the major cultivation areas during the past five decades. Precipitation showed little change, but exhibited clear fluctuations. Since 2000, the annual precipitation each year was less than in the previous years. Total solar radiation showed a decreasing trend $\left(-63.3 \mathrm{MJ} / \mathrm{m}^{2} \cdot \mathrm{a}\right)$ during the entire period and, since the 1980 s, the annual solar radiation was less than the mean solar radiation for the entire period.

Maps of climate change trends show the spatial distribution of climate change from 1961 to 2010 (Figure 6). Mean temperature generally increased across the major cultivation areas. In particular, it increased by an average rate of more than $0.3^{\circ} \mathrm{C} /$ decade in the northern arid and semiarid region, the Northeast China Plain, the Qinghai-Tibet Plateau, and the Loess Plateau. In contrast, the Sichuan Basin and the surrounding regions had the lowest mean temperature increase, $0.1^{\circ} \mathrm{C} /$ decade. Precipitation increased primarily in southern China and the Middle-lower Yangtze Plain by 21.7 and $9.7 \mathrm{~mm} /$ decade, respectively. In northwestern China, the precipitation declined in some locations. In contrast, precipitation generally decreased in the other major farmland areas. In particular, the Loess Plateau showed the largest decrease, of $20.5 \mathrm{~mm} /$ decade. Solar radiation decreased in large areas across the major farmland regions. The HuangHuai-Hai Plain had the largest decrease, $111.5 \mathrm{MJ} / \mathrm{m}^{2}$. decade. Solar radiation decreased in the Middle-lower Yangtze Plain, southern China, and the Sichuan Basin. In contrast, solar radiation showed an increasing trend in a small section of 


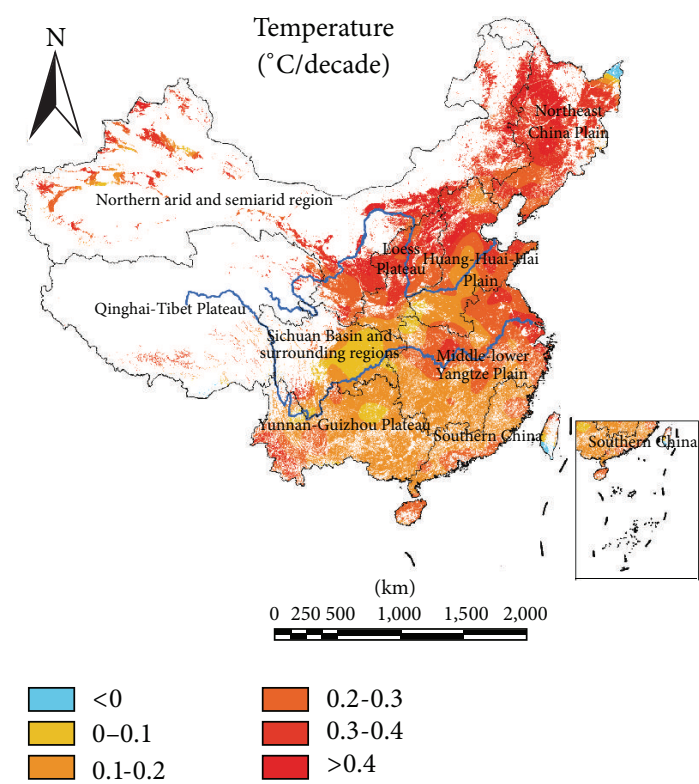

(a)

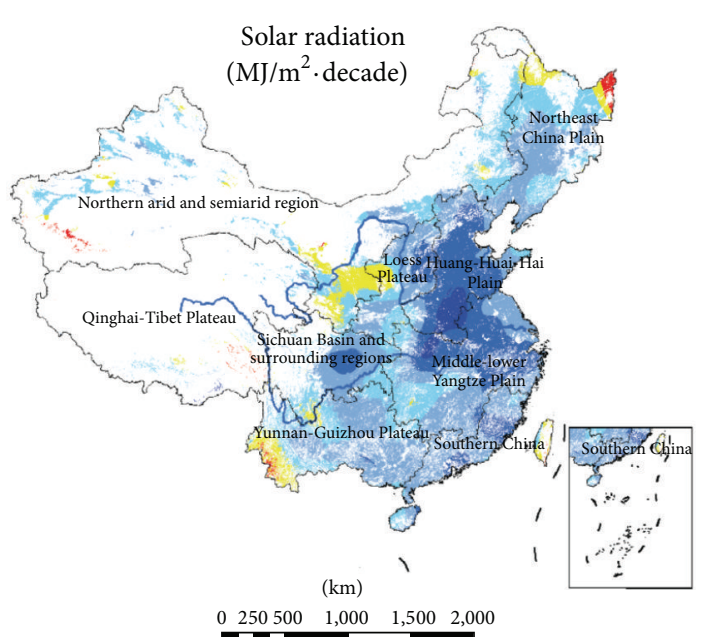

\section{$>50$}

$0-50$

$-50-0$

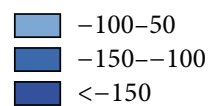

(c)

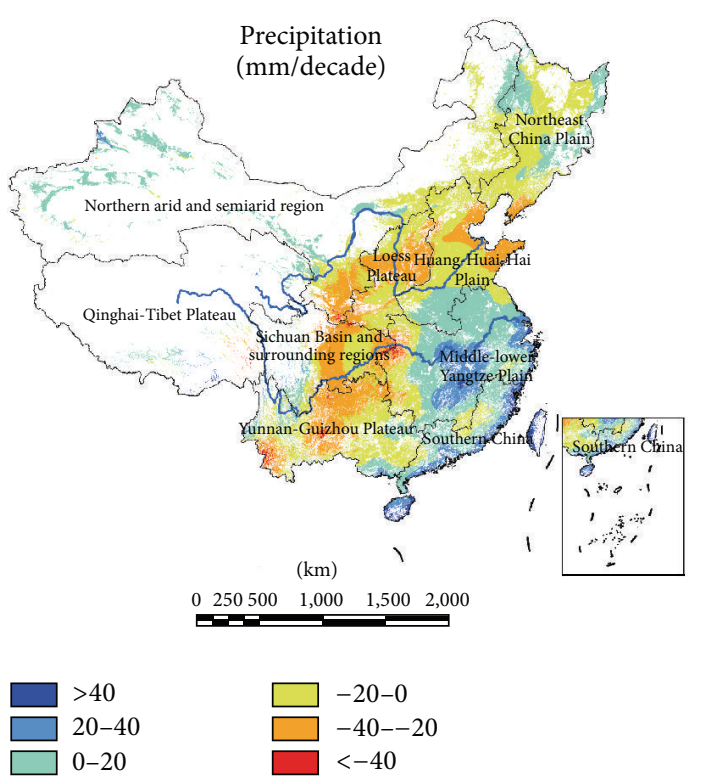

(b)

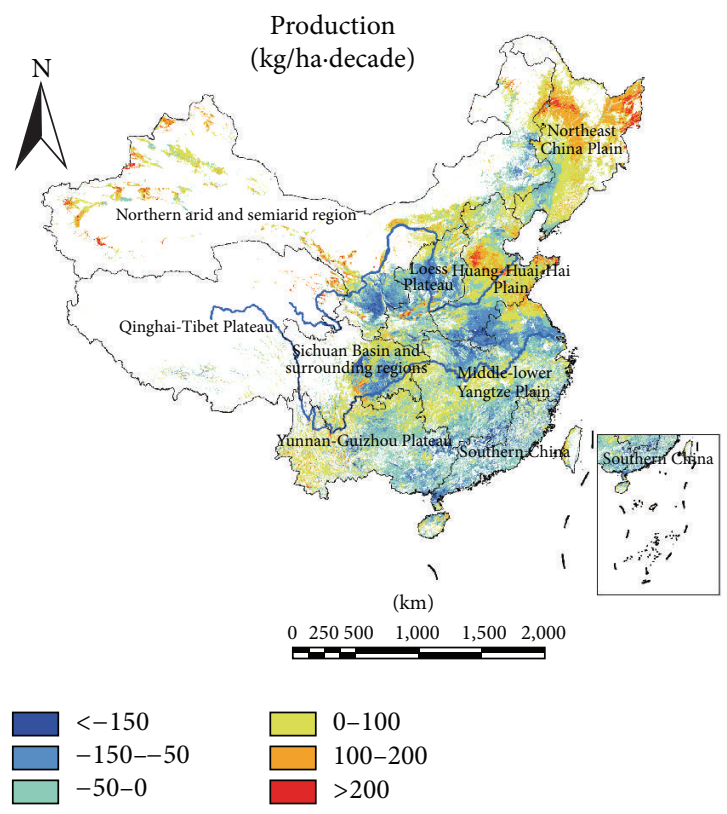

(d)

FIGURE 6: Changes in climatic factors and production potential during the past five decades.

northern Heilongjiang Province and in southwestern Yunnan Province.

3.4. Impact of Climate Change on Production Potential. The spatial heterogeneity of climate change during the past five decades had a significant impact on production potential in China (Figure 6). For the entirety of China, the production potential increased by $\sim 1.58$ million tons/decade as a result of climate change. The geographic distribution of production potential changed over the past five decades, with increases in the north and decreases in the south. The areas with increased production potential were located mainly in the Northeast China Plain, the northern arid and semiarid region, and the Huang-Huai-Hai Plain, where production potential increased by $3.15,0.92$, and 0.79 million tons/decade, respectively. In contrast, the areas with decreased production potential were located mainly in the Middle-lower Yangtze Plain and southern China, where production potential decreased by 1.53 and 0.83 million tons/decade, respectively.

To analyze the relationship between the changes in production potential and the changes in each climate factor in different regions, correlation coefficients between the production potential and each climatic factor were calculated for each grid.

The change in temperature had a large impact on production potentials, but with different effects in different areas. In 
the Northeast China Plain and the Huang-Huai-Hai Plain, the warming trend had a positive effect on the production potential due to increased plant biomass production over the course of the growing season. In the Huang-Huai-Hai Plain, the production potential was increased further by changes in multiple cropping systems made in response to the temperature increase. In contrast, the correlation coefficient between the temperature and the production potential was negative in the Loess Plateau, southern China, and the Yunnan-Guizhou Plateau. Because heat was already sufficient in southern China and the Yunnan-Guizhou plateau, crops did not respond to the increase in temperature with additional growth. The increase in temperature also accelerated crop growth and reduced the required length of the growing season, resulting in a decrease in the production potential. Given the inadequate moisture levels in the Loess Plateau due to low irrigation rates and precipitation, the increase in temperature caused higher evapotranspiration rates, leading to reduced production potential. In contrast, the increase in the temperature had little impact on the production potential in the Middle-lower Yangtze Plain. In summary, the trend for increasing temperature over the past five decades had a positive impacton the production potential in the higher latitudes but had a negative impact on that at the lower latitudes.

The correlation coefficients between precipitation and the production potential were different in the southern and northern regions of China (Figure 7). In northern China, the production potential showed a positive correlation with precipitation, particularly for the rain-fed cropland. However, the limited supply of water in the arid climate of northern China resulted in a decrease in the production potential associated with the trend for decreasing precipitation. In southern China, precipitation and production potential were negatively correlated. An associated effect of excessive rainfall was a decline in solar radiation, which was a significant factor in the decrease in production potential. During the past five decades, the trend in precipitation across China as a whole showed little change but displayed clear geographic differences. Precipitation decreased in northern China and increased in southern China, resulting in a net decrease in the national total production potential.

In southern China and the coastal area of North China, the production potential showed a positive correlation with solar radiation because the abundant water supply supported high rates of photosynthesis, leading to increasing plant biomass with increasing solar radiation. In contrast, solar radiation and production potential were correlated negatively in northern China. The increase in solar radiation may have accelerated the rate of evaporation leading to water deficit in crops. Although northeastern China is an arid region, most of the agricultural production is irrigated so the increase in solar radiation had less impact on the water requirements of the crops. Therefore, the solar radiation and the production potential were positively correlated.

We established a linear regression model using the climatic factors as independent variables and the production potential as a dependent variable to identify the primary factors that impact the production potential. The increase in temperature had a large and positive influence on the production potential. The contribution rate of temperature to the production potential reached $2137.00 \%$ among three factors, while the decreases in precipitation and solar radiation had negative impacts on the production potential, and their contribution rates were $-388.06 \%$ and $-1648.94 \%$, respectively. The increase in temperature was the major contributing factor to the increase in production potential when considering China as a whole, but temperature, precipitation, and solar radiation had varying effects on the production potential in specific regions. In the Northeast China Plain, the increase in temperature was the major factor in the increased production potential, and the contribution rate of temperature to the production potential reached $104.38 \%$. In the northern arid and semiarid region, temperature and precipitation were the major factors in the changes in production potential, but their effects were antagonistic. The increase in temperature had a positive impact on the production potential, with a contribution rate of $431.15 \%$, while the decrease in the temperature had a negative influence on the production potential, and its contribution rate was $290.18 \%$. In southern China, the increased temperature and decreased solar radiation caused a decrease in the production potential, with contribution rates of $53.12 \%$ and $48.62 \%$, respectively. In the Middle-lower Yangtze Plain, the decrease in solar radiation was the major factor causing the decrease in the production potential, with a contribution rate of $186.99 \%$. In the Huang-Huai-Hai Plain, the changes in temperature and solar radiation had large and opposing effects on the production potential. The increase in temperature resulted in an increase in production potential, with a contribution rate of $271.38 \%$, but the decrease in solar radiation had a negative impact on the production potential, with a contribution rate of $-118.98 \%$ (Table 1 ).

\section{Conclusion and Discussion}

China faces challenges to its efforts to ensure grain security resulting from an increasing population and the decreasing availability of land for agriculture. One important factor that puts grain security at risk is the high level of climatic variability. Temperature, precipitation, and solar radiation are key climate variables that determine the amount of plant biomass production. In this study, we analyzed the impacts of temperature, precipitation, and solar radiation variability on the agricultural production potential of five major crops in China based on the GAEZ model using meteorological data, including terrain elevation and soil data, collected over the past five decades. Conclusions from this study are as follows.

(1) In 2010, the total production potential was 1.17 billion tons in China, and the per hectare production potential was $7,889 \mathrm{~kg} / \mathrm{ha}$. The production potential increased from north to south and from west to east. The region with the highest total and per hectare production potential was the Middlelower Yangtze Plain, with 0.30 billion tons and $10,789 \mathrm{~kg} / \mathrm{ha}$, respectively.

(2) Changes in annual temperature, precipitation, and solar radiation showed different trends over the past five 


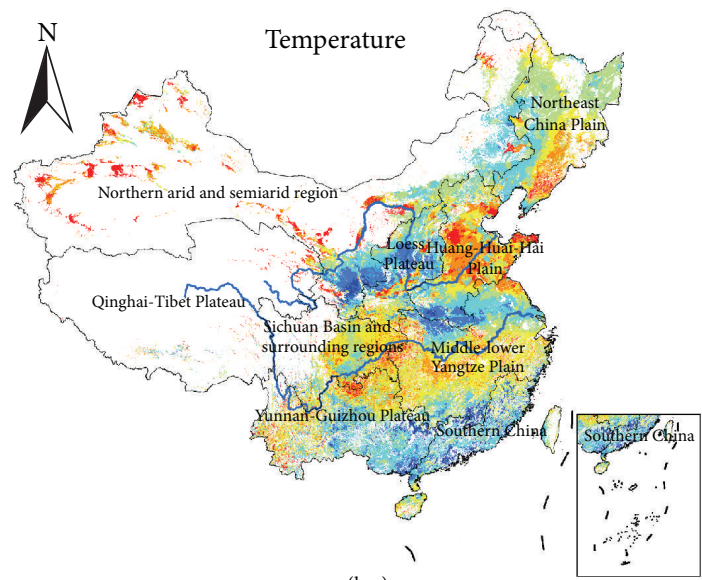

$(\mathrm{km})$

$\begin{array}{lllll}0 & 250500 & 1,000 & 1,500 & 2,000\end{array}$

들

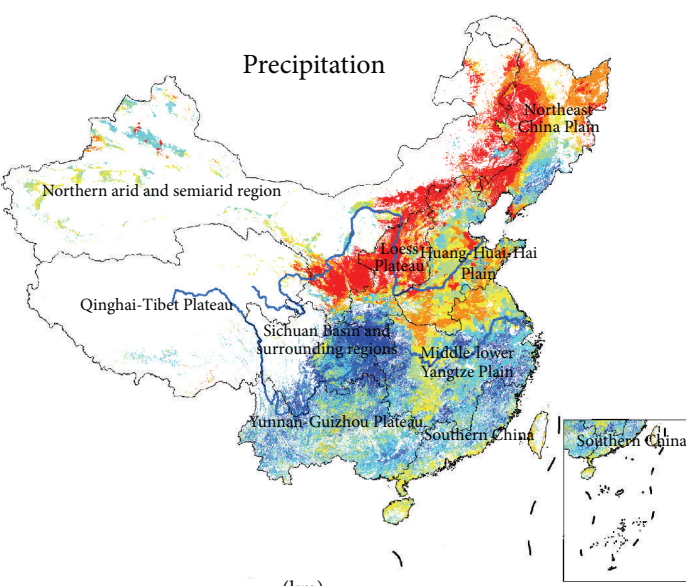

$(\mathrm{km})$ $\begin{array}{r}0 \quad 250500 \quad 1,000 \quad 1,500 \quad 2,000 \\ \hline\end{array}$

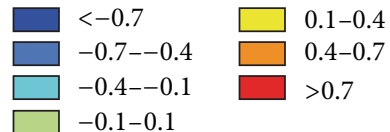

(b)

(a)

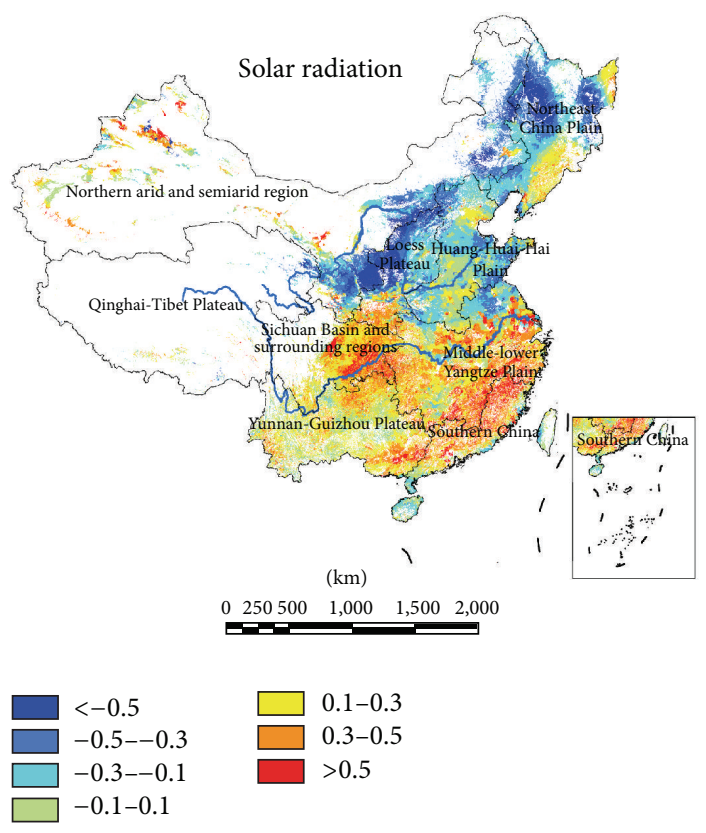

(c)

FIGURE 7: Correlation coefficients between production potential and climatic factors.

decades. Temperature showed a clear increasing trend with a dramatically increased rate of temperature change after the late 1980s. Precipitation showed minor change overall but exhibited substantial fluctuation. After 2000, the annual precipitation was consistently less than that in the previous years. Solar radiation showed an obvious decreasing trend during the entire period and the annual solar radiation since the 1980s was consistently less than the mean solar radiation over the past five decades.

(3) The geographic heterogeneity of climate change had a significant impact on the production potential in China. The overall production potential increased by approximately 1.58 million tons/decade in response to climate change. The areas with increased production potential were located 
TABLE 1: Contributions of climatic factors to the production potential in various regions of China (\%).

\begin{tabular}{lccc}
\hline Agriculture zone & Temperature & Precipitation & Radiation \\
\hline Northeast China Plain & 104.38 & -24.64 & 20.26 \\
Yunnan-Guizhou Plateau & 102.07 & -122.52 & 120.45 \\
Northern arid and semiarid region & 431.15 & -290.18 & -40.97 \\
Southern China & 53.12 & -1.74 & 48.62 \\
Sichuan Basin and surrounding regions & 23.12 & -381.43 & 458.31 \\
Middle-lower Yangtze Plain & -58.04 & -28.95 & 186.99 \\
Qinghai-Tibet Plateau & 78.86 & 12.68 & 8.47 \\
Loess Plateau & -60.65 & 161.33 & -0.67 \\
Huang-Huai-Hai Plain & 271.38 & -52.40 & -118.98 \\
Total & $\mathbf{2 1 3 7 . 0 0}$ & $-\mathbf{3 8 8 . 0 6}$ & $-\mathbf{1 6 4 8 . 9 4}$ \\
\hline
\end{tabular}

mainly in the Northeast China Plain, the northern arid and semiarid region, and the Huang-Huai-Hai Plain. In contrast, the areas with decreased production potential were located mainly in the Middle-lower Yangtze Plain and southern China.

(4) The effects of the climate factors that impact production potential in China varied greatly. In the Northeast China Plain, the increase in temperature was the major factor in the increased production potential. In the northern arid and semiarid region, temperature and precipitation were the major factors that led to changes in production potential, but their effects were in opposition to each other. In southern China, the increase in temperature and the decrease in solar radiation led to decreased production potential. In the Middle-lower Yangtze Plain, the major factor causing decreased production potential was the decrease in solar radiation. In the Huang-Huai-Hai Plain, the changes in temperature and solar radiation had large and opposite effects on the production potential.

Finally, we note the limitations of this study. Extreme weather conditions (i.e., freezing or high temperatures, rainstorms, or heavy snow) may have an extreme effect on the production potential, but these factors were not taken into consideration in our study. The irrigated scenarios in this study assumed a sufficient supply of water for crop growth, but the actual availability of water provided by irrigation still poses limitations to crop growth in practice. Crop species selection is determined, in large part, based on farmers' financial interests and not necessarily on which crop is the most suitable.

\section{Conflict of Interests}

The authors declare that they have no conflict of interests.

\section{Acknowledgments}

This research was supported and funded by the National Key Project of Scientific and Technical Supporting Programs (no. 2013BAC03B01), the project of CAS action-plan for West Development (no. KZCX2-XB3-08-01), and the National Program on Key Basic Research Project (973 Program) (no. 2010CB950901). The authors are particularly indebted to Günther Fisher from IIASA for his GAEZ model. He made substantial contribution to the production potential estimation of China.

\section{References}

[1] S. Susan, "Climate change 2007-the physical science basis: working group I contribution to the fourth assessment report of the IPCC," Tech. Rep., Cambridge University Press, 2007.

[2] H. C. J. Godfray, J. R. Beddington, I. R. Crute et al., "Food security: the challenge of feeding 9 billion people," Science, vol. 327, no. 5967, pp. 812-818, 2010.

[3] J. Liu, Z. Zhang, X. Xu et al., "Spatial patterns and driving forces of land use change in China during the early 21st century," Journal of Geographical Sciences, vol. 20, no. 4, pp. 483-494, 2010.

[4] L. R. Brown, Who Will Feed China?: Wake-Up Call for a Small Planet, WW Norton \& Company, 1995.

[5] M. E. Brown and C. C. Funk, "Climate: food security under climate change," Science, vol. 319, no. 5863, pp. 580-581, 2008.

[6] H. F. Gale Jr., China's Food and Agriculture: Issues for the 21st Century, 2012.

[7] A. J. Challinor, E. S. Simelton, E. D. Fraser, D. Hemming, and M. Collins, "Increased crop failure due to climate change: assessing adaptation options using models and socio-economic data for wheat in China," Environmental Research Letters, vol. 5, no. 3, Article ID 034012, 2010.

[8] S. Barry and Y. Cai, "Climate change and agriculture in China," Global Environmental Change, vol. 6, no. 3, pp. 205-214, 1996.

[9] F. Tao, Z. Zhang, S. Zhang, Z. Zhu, and W. Shi, "Response of crop yields to climate trends since 1980 in China," Climate Research, vol. 54, pp. 233-247, 2012.

[10] J. Alcamo, N. Dronin, M. Endejan, G. Golubev, and A. Kirilenko, "A new assessment of climate change impacts on food production shortfalls and water availability in Russia," Global Environmental Change, vol. 17, no. 3-4, pp. 429-444, 2007.

[11] E. I. Teixeira, G. Fischer, H. van Velthuizen, C. Walter, and F. Ewert, "Global hot-spots of heat stress on agricultural crops due to climate change," Agricultural and Forest Meteorology, vol. 170, pp. 206-215, 2011.

[12] J. Liu, M. Liu, H. Tian et al., "Spatial and temporal patterns of China's cropland during 1990-2000: an analysis based on Landsat TM data," Remote Sensing of Environment, vol. 98, no. 4, pp. 442-456, 2005. 
[13] J. Liu, M. Liu, D. Zhuang, Z. Zhang, and X. Deng, "Study on spatial pattern of land-use change in China during 1995-2000," Science in China Series D, vol. 46, no. 4, pp. 373-384, 2003.

[14] J. Liu, H. Tian, M. Liu, D. Zhuang, J. M. Melillo, and Z. Zhang, "China's changing landscape during the 1990s: largescale land transformations estimated with satellite data," Geophysical Research Letters, vol. 32, no. 2, 2005.

[15] J. Liu, Q. Zhang, and Y. Hu, "Regional differences of China's urban expansion from late 20th to early 21st century based on remote sensing information," Chinese Geographical Science, vol. 22, pp. 1-14, 2012.

[16] M. F. Hutchinson, "Interpolation of rainfall data with thin plate smoothing splines-part I: two dimensional smoothing of data with short range correlation," Journal of Geographic Information and Decision Analysis, vol. 2, pp. 139-151, 1998.

[17] M. F. Hutchinson, "Interpolation of rainfall data with thin plate smoothing splines-part II: analysis of topographic dependence," Journal of Geographic Information and Decision Analysis, vol. 2, pp. 152-167, 1998.

[18] A. Shortridge and J. Messina, "Spatial structure and landscape associations of SRTM error," Remote Sensing of Environment, vol. 115, no. 6, pp. 1576-1587, 2011.

[19] G. Fischer, M. Shah, F. N. Tubiello, and H. van Velhuizen, "Socio-economic and climate change impacts on agriculture: an integrated assessment, 1990-2080," Philosophical Transactions of the Royal Society B, vol. 360, no. 1463, pp. 2067-2083, 2005.

[20] G. Fischer, M. Shah, H. Velthuizen, and F. Nachtergaele, "Agroecological zones assessments. Land use and land cover," in Encyclopedia of Life Support Systems (EOLSS), Developed Under the Auspices of the UNESCO, Eolss, Oxford, UK, 2006.

[21] G. Fischer and L. X. Sun, "Model based analysis of future land-use development in China," Agriculture, Ecosystems \& Environment, vol. 85, no. 1-3, pp. 163-176, 2001.

[22] G. Fischer, H. Van Velthuizen, M. Shah, and F. Nachtergaele, Global Agro-Ecological Assessment for Agriculture in the 21st Century: Methodology and Results, International Institute for Applied Systems Analysis, 2002.

[23] H. Yan, J. Liu, and M. Cao, "Remotely sensed multiple cropping index variations in China during 1981-2000," Acta Geographica Sinica, vol. 60, no. 4, pp. 559-566, 2005.

[24] FAO, "Guidelines: land evaluation for rain-fed agriculture," FAO Soils Bulletin 52, 1984.

[25] FAO, "Guidelines: land evaluation for irrigated agriculture," FAO Soils Bulletin 55, 1985. 

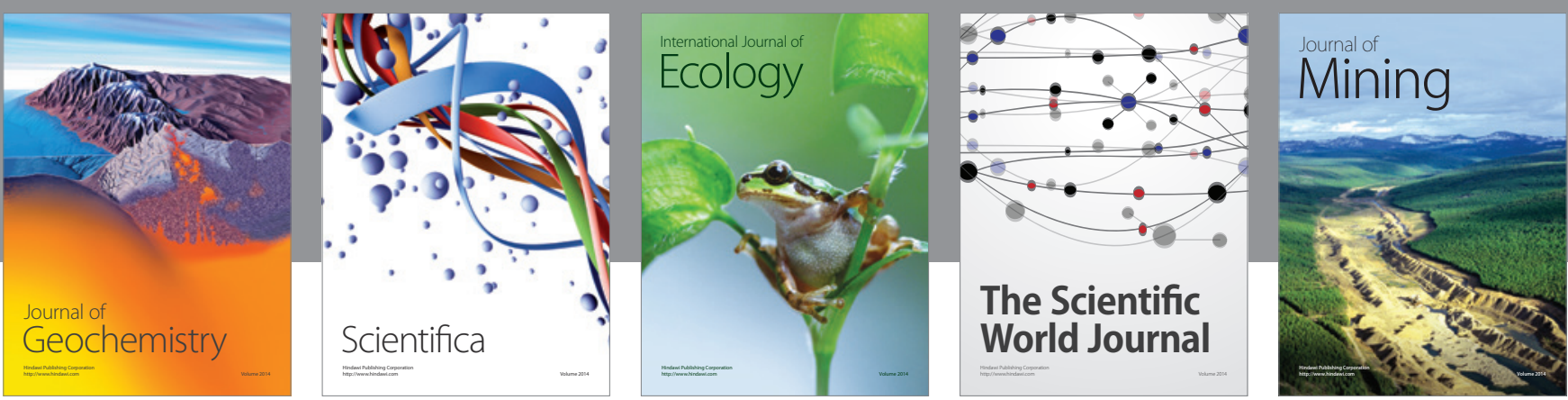

The Scientific World Journal
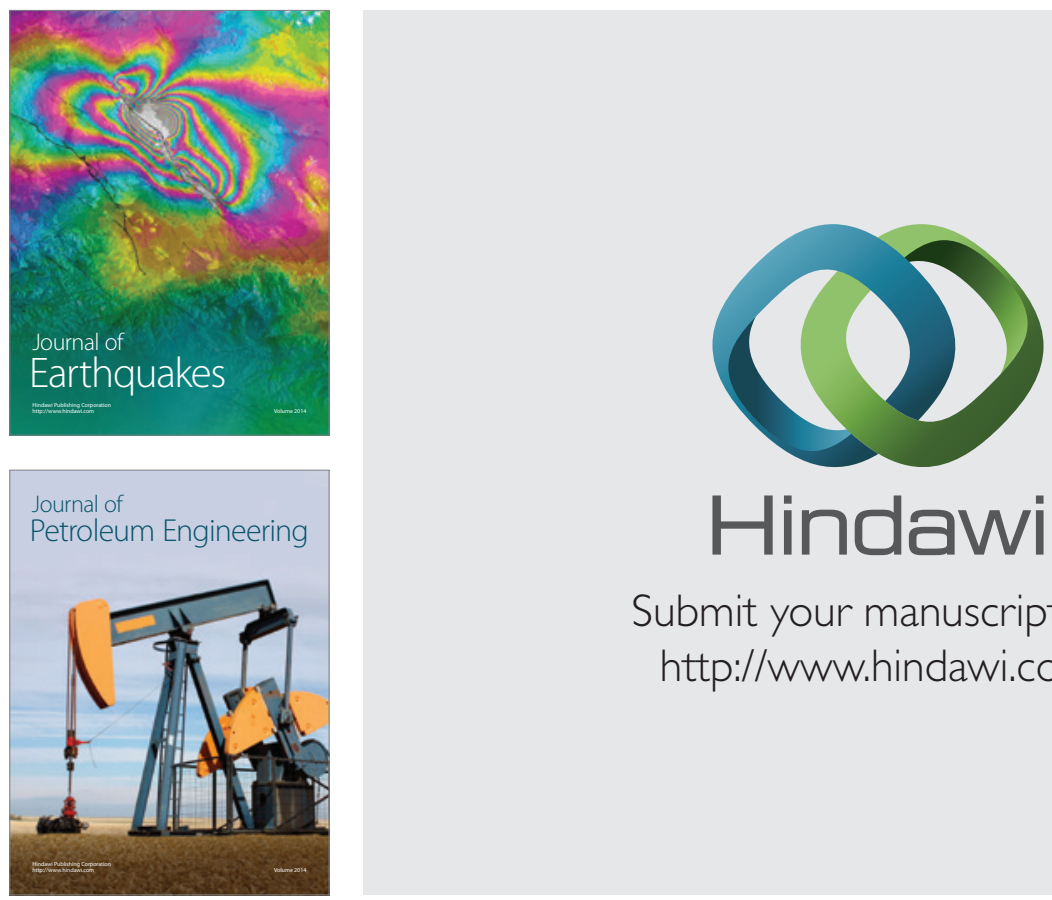

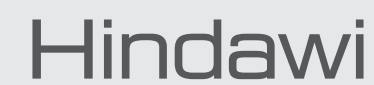

Submit your manuscripts at

http://www.hindawi.com
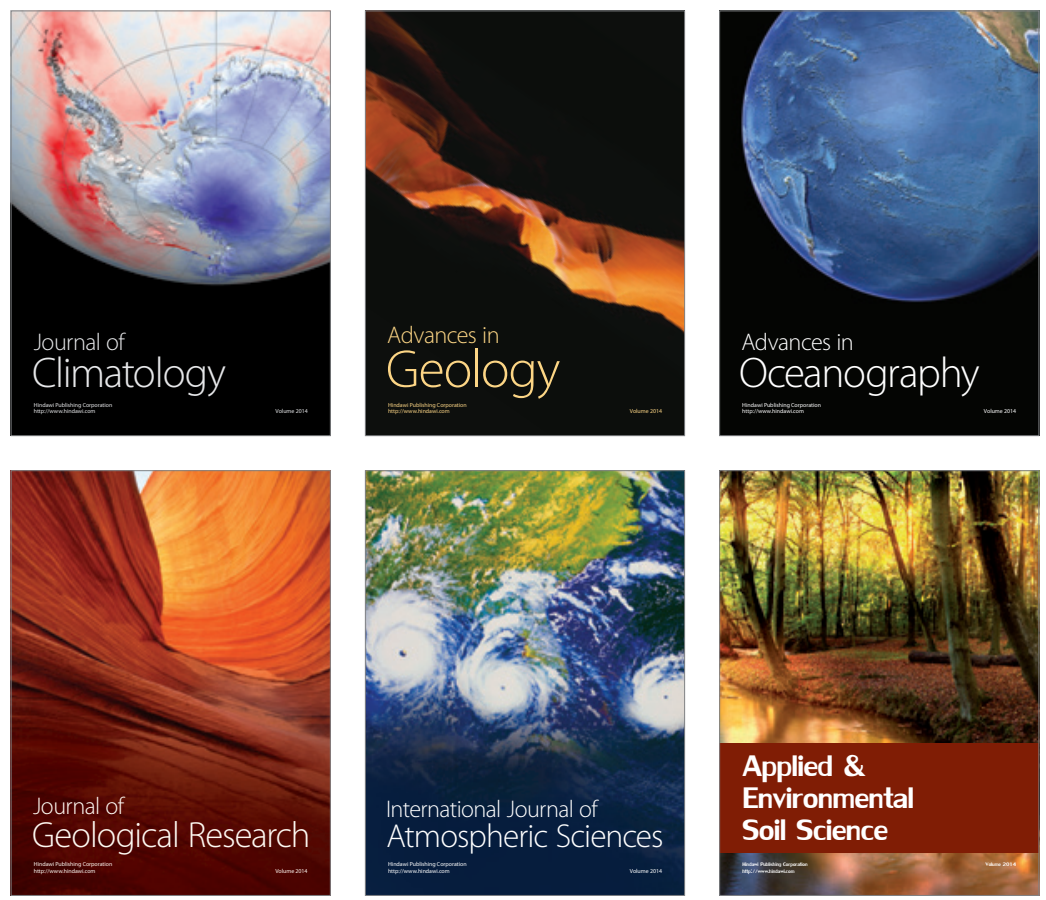
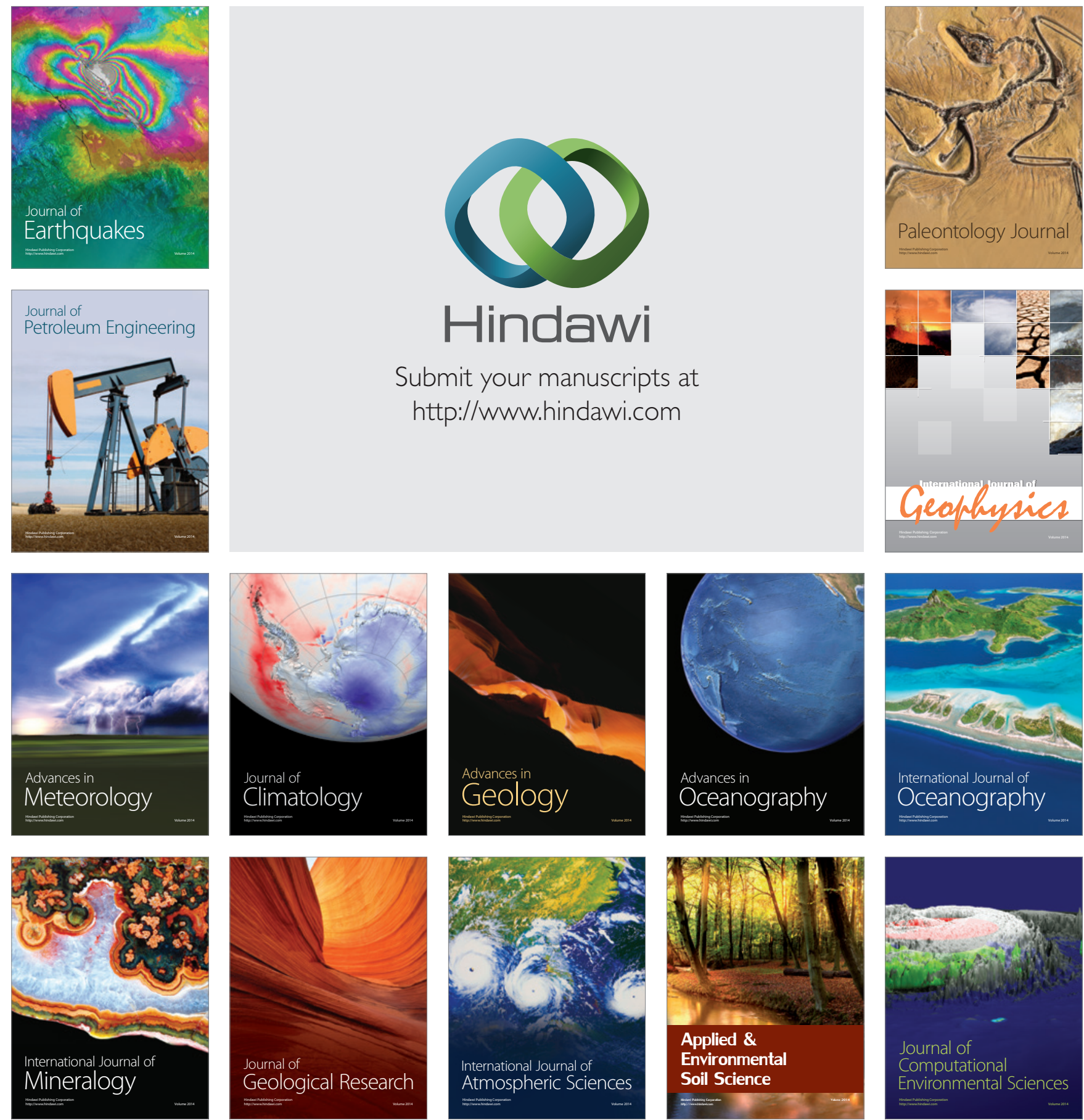